\title{
Effect of fertilizer application on winter wheat productivity under precision agriculture in Kazakhstan
}

\author{
ALIBEK BAIMURATOV ${ }^{1, \bullet}$, SHOLPAN BASTAUBAYEVA ${ }^{2}$, MEHMET ARSLAN ${ }^{3}$, ZHANAR YERALIYEVA $^{4}$ \\ ${ }^{1}$ Kazakh National Agrarian University. Abay Avenue, 8, Almaty, 050010, Kazakhstan. `email: alibek.baimuratov@bk.ru \\ ${ }^{2}$ Kazakh Research Institute of Agriculture and Plant Growing, Erlepesova street 1, Almalybak Village, Karasay District, Almaty Region, 040909, Kazakhstan \\ ${ }^{3}$ Erciyes University. Kayseri, 38039, Turkey \\ ${ }^{4}$ Kazakh National Women's Teacher Training University. Aiteke bi street 99, Almaty, 050000, Kazakhstan
}

Manuscript received: 25 December 2020. Revision accepted: 28 February 2021.

\begin{abstract}
Baimuratov, A, Bastaubayeva S, Arslan M, Yeraliyeva Z. 2021. Effect of fertilizer application on winter wheat productivity under precision agriculture in Kazakhstan. Biodiversitas 22: 1558-1563. The effect of mineral fertilization of light chestnut soils of Almalybak, Kazakhstan on the three winter wheat varieties grain yields and NDVI was carried out in 2017/18, 2018/2019 as well as 2019/2020 growing seasons using precision agriculture technologies. The experiments were set up in an incomplete factorial design with rates of NPK N90P60K45, N120P90K60, and N150P120K90. Agrochemical cartograms were ordered for the substance of effectively hydrolyzable nitrogen, extractable phosphorus, and exchangeable potassium. The total variation of NDVI was from 0.62 in the minimum (Bezostaya 100 variety, 2017/18) to 0.88 in the maximum (Aliya variety, 2019/20) in the flowering phase of wheat plants. The highest index of NDVI was observed in the N150P120K90 in the three winter wheat varieties for the three seasons. Studies directed in multivariate analyses built up the connection between fertilizer application, soil fruitfulness, and grain yield. As per the genuine heterogeneity of the fields, standards were determined and differential use of the fundamental phosphorus fertilizer was completed. The yield for the winter wheat varieties varied between 5.6-5.9 t/ha for Aliya variety, 6.5-7.0 t/ha for Grom, and 6.2- 6.7 t/ha for Bezostaya 100 , which presents that P120 doses were more suitable in experimental plots for winter wheat varieties. The grain yield on mineral fertilization of NPK for the studied varieties varied from 4.2 to $7.6 \mathrm{t} / \mathrm{ha}$ for Aliya variety, from 4.0 to $6.8 \mathrm{t} / \mathrm{ha}$ for the Bezostaya 100 , and from 4.5 to $7.9 \mathrm{t} / \mathrm{ha}$ for Grom. The highest grain yield was observed in the N150P120K90 for three winter wheat varieties in all three seasons.
\end{abstract}

Keywords: Grain yield, NDVI, nitrogen, phosphorus, potassium

\section{INTRODUCTION}

Conventional farming has negative environmental impacts such as soil erosion, soil degradation, and groundwater pollution because of the extensive use of chemicals. Farming systems should be more sustainable to reach economic and social profitability as well as environmental preservation. A possible solution to this problem is precision agriculture, which helps to get sustainable agricultural production without damaging the environment. Precision technologies are used to get information about differences within the agricultural field in order to match inputs to site-specific field conditions (Diacono et al. 2013).

The introduction of modern technologies in improving agricultural efficiency requires precision farming technologies. Precision agriculture can provide a management approach optimizing both agricultural production and profitability-which is the key goal of most farming enterprises. Additionally, part of profitability can come from the reduced use of inputs (machinery, labor, fertilizer, chemicals, seeds, water, energy, etc.), leading to both cost savings and also environmental benefits (ZarcoTejada et al. 2014).

Digitalization in agriculture means the widespread adoption of precision farming technologies and agro- technological decision-making systems, which depend on monitoring and processing data from multiple sources in order to optimize the productivity, profitability, and sustainability of agricultural enterprises (Mousazadeh 2013; Yakushev 2020).

Precision farming is becoming a growing management practice, as it is linked to key factors directly related to global issues such as sustainable agriculture and food security (Gebbers and Adamchuk 2010). The basis of the scientific concept of precision farming is the idea of the existence of heterogeneities within a single agricultural land. Navigation systems permit deciding plant biomass, nutrient substance, fertilizer take-up, and location, which are necessary parameters for application of fertilizers. Evaluation of the nitrogen, phosphorus, and potassium, biomass, and nitrogen take-up of plants from the soil by contact optical estimations is a promising method for improving agricultural productivity (Schmidhalter et al. 2008).

The soil heterogeneity is mainly affected by topography, vegetation, climate, biological conditions, and land-use changes and such as agriculture. To identify the soil heterogeneities, scientists use the latest global positioning technologies, satellite and drone images, as well as special programs designed for agro-management. The obtained data are used for sowing planning, calculation 
of fertilizer application rates and plant protection products, accurate yield prediction, as well as financial planning (Truflyak 2016). The use of precision farming technologies allows saving resources by $20-30 \%$, which significantly increases the efficiency and environmental indicators of land use (Zarco-Tejada et al. 2014; Meena et al. 2019).

In recent years, the management of the crop production process has been carried out using biological methods and modern navigation equipment. This allows you to timely and differentially carry out agricultural activities, quickly and directionally manage the laying and formation of productivity elements, crop size, and product quality (Martínez-Castillo 2016).

Kazakhstan is an agriculture-dependent country. For the priority field crops of the south-east of the country, technologies for differentiated effects on soil and plants were first developed in the irrigated soil and they were recommended to rural producers depending on the level of their technical equipment and financial capabilities (high, medium, low), with the aim to increase crop productivity and quality of products. In this setting, the pioneer study was carried out by Suleimenova et al. (2020a) on important and priority crops of the region using precision agriculture.

Winter wheat is an important crop in Central Asia, including Kazakhstan. Usual national production of wheat grain of Kazakhstan is $18-20$ million tons, but the production is highly dependent on weather and in recent years it has fluctuated between 10 and 17 million tons. The crop is grown under both irrigated and rainfed conditions and wheat of Kazakhstan is popular for its high quality (Kokhmetova et al. 2014; Morgounov et al. 2015).

According to Kazakh soil scientists (Bastaubayeva and Ramazanova 2019), the use of fertilizers, considering the state of development of plants of grain crops, is an effective method of influencing the nutritional regime of irrigated light chestnut soils, as well as the growth, development of plants and grain yield. Using fertilizers in critical periods of organogenesis, one can directionally optimize the laying of the leaf surface, the dynamics of the formation of biomass, and therefore manage the productivity of grain crops. It is noted that when using nitrogen fertilizers, the number of productive wheat shoots increases 1.5-2.0 times, their loss decreases by 25.0-53.1\%, the proportion of shoots completing the full development cycle increases to 76.3-94.4\% compared to control. Under the influence of nitrogen fertilizers, the grain yield of wheat increased by 1.3-2.1 times. Romaneckas et al. (2015) summarized that under precision agriculture the quantity of $\mathrm{P}_{2} \mathrm{O}_{5}$ was the soil under spring wheat plants varied from 108 to $212 \mathrm{mg} \mathrm{kg}^{-1}, \mathrm{~K}_{2} \mathrm{O}$ - from 97 to $143 \mathrm{mg} \mathrm{kg}^{-1}, \mathrm{pH}-$ from 6.5 to 7.4 with comparison to conventional conditions.

A program has been developed for the differential application of fertilizers, considering the actual heterogeneity of the fields and the level of intensification of technologies for the cultivation of new high-yielding varieties of winter wheat. This article presented the results obtained using different doses of mineral nitrogen, phosphorus, and potassium fertilizers in the precision farming system on irrigated land in the south of Kazakhstan. The aim of current study was to investigate the effects of mineral fertilization of NPK on the yields of winter wheat varieties and NDVI index of wheat fields.

\section{MATERIALS AND METHODS}

The field experiment was carried out at irrigated lands of the Kazakh Research Institute of Agriculture and Plant growing (KazRIAPG), located in the foothill-steppe zone (4313'09" N;76 ०41'17"E) during 2017/18, 2018/19, $2019 / 20$ growing seasons. The area of experiment location covers 38 ha, out of which 12.22 ha is generally covered by winter wheat.

The soil of the experimental plot is light chestnut, composed of medium loam. The content of the main nutrients along the soil horizons is presented in Table 1. It can be seen from this table that the humus content in the arable horizon is $2.44 \%$, the amount of which sharply decreases down the profile. There is a high content of carbonates $\left(\mathrm{CO}_{2}\right)$, quantitatively increasing from $2.5 \%$ in the $0-22 \mathrm{~cm}$ layer to $4.7 \%$ in the $40-68 \mathrm{~cm}$ layer. Due to the high carbonate content, the reaction of the soil solution is slightly alkaline $\mathrm{pH}-7.3-7.5$. In the arable layer, the total nitrogen is $0.15 \%$, phosphorus $0.21 \%$ and their number in the lower horizons gradually decreases.

According to the degree of availability of nutrients, the experimental site is characterized as very low, low, medium, increased and high contents of nitrogen, a medium increased, high and very high content of phosphorus, a very low, low medium, and increased content of potassium (Figure 1) according to plot location.

Table 1. Chemical composition of light chestnut soil

\begin{tabular}{|c|c|c|c|c|c|c|c|}
\hline \multirow{2}{*}{$\begin{array}{c}\begin{array}{c}\text { Soil horizon } \\
\text { depth }(\mathbf{c m})\end{array} \\
\end{array}$} & \multirow{2}{*}{$\begin{array}{c}\text { Humus } \\
(\%)\end{array}$} & \multicolumn{4}{|c|}{ Nutrients (\%) } & \multicolumn{2}{|c|}{ Mobile forms of nutrients $\left(\mathrm{mg} \mathrm{kg}^{-1}\right)$} \\
\hline & & $\mathbf{N}$ & $\mathbf{P}$ & $\mathrm{CO}_{2}$ & pH & $\mathbf{P}_{2} \mathbf{O}_{5}$ & $\mathrm{~K}_{2} \mathrm{O}$ \\
\hline $0-22$ & 2.44 & 0.15 & 0.214 & 2.5 & 7.3 & 26.8 & 414.0 \\
\hline $22-40$ & 1.70 & 0.11 & 0.198 & 3.4 & 7.3 & 12.7 & 326.4 \\
\hline $40-68$ & 1.07 & 0.06 & 0.191 & 4.7 & 7.5 & 4.8 & 182.7 \\
\hline
\end{tabular}



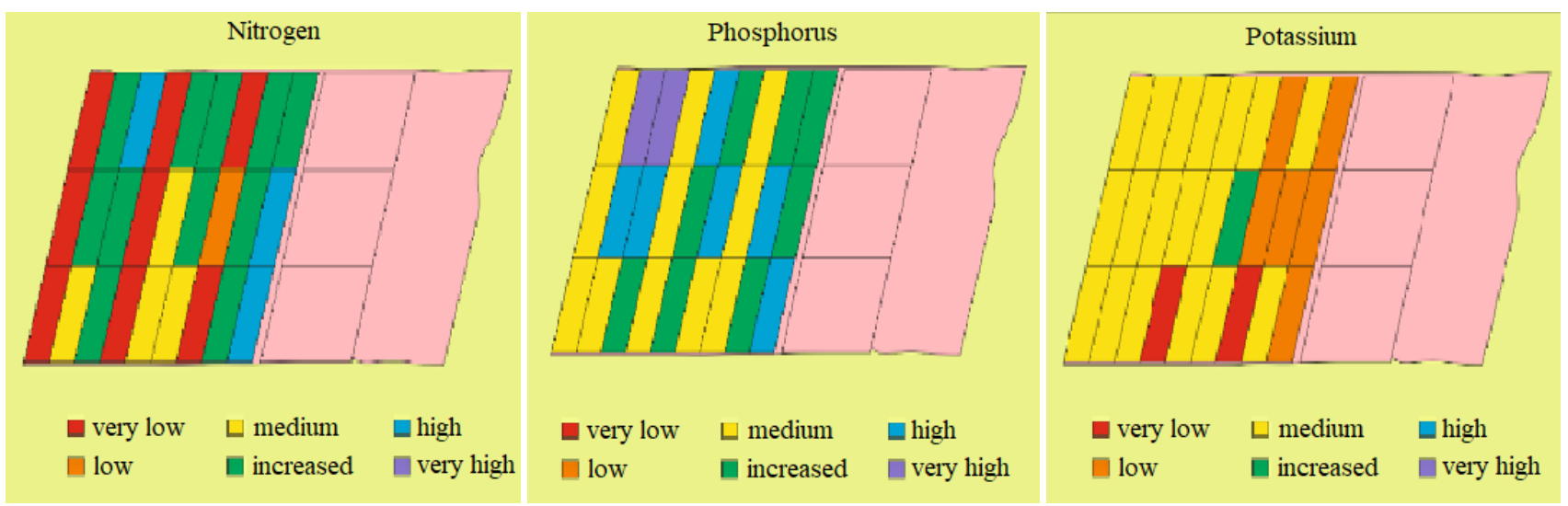

Figure 1. Plot map of the contents of nitrogen, phosphorus, and potassium in experimental field plots

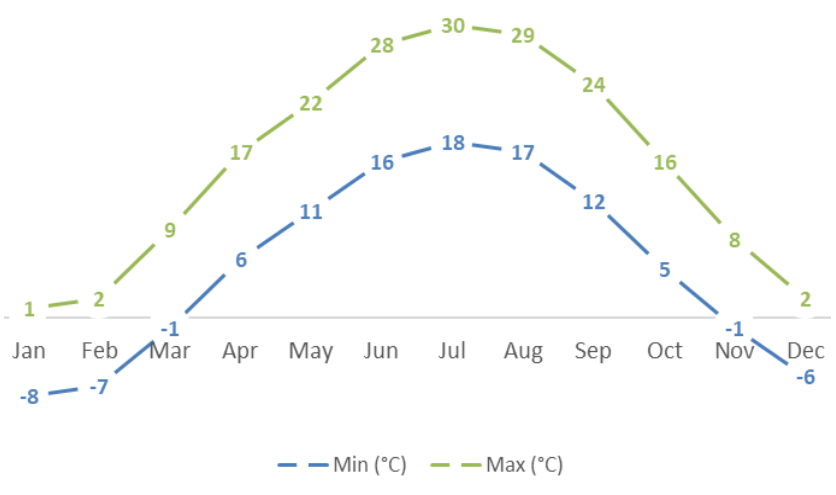

Figure 2. Monthly maximum and minimum temperature range in Almalybak, Kazakhstan

The climate of the zone is sharply continental, and the site is located at 800 meters $(2,600$ feet) above sea level. Here, the average temperature ranges from $-8{ }^{\circ} \mathrm{C}$ in January to $30{ }^{\circ} \mathrm{C}$ in July (Figure 2); there is often a large temperature range between night and day. During winter the temperature can plunge to $-30^{\circ} \mathrm{C}$ at worst. Because of the location at the foot of the mountains, precipitation is more abundant than in other parts of the country and amounts to $585 \mathrm{~mm}$ per year, with a maximum in spring, between March and May. The average long-term precipitation (from 1961 to 2020) for the year is $415 \mathrm{~mm}$ with fluctuations in some years from 300 to $500 \mathrm{~mm}$.

During the growing season from September 2017 to August 2018, total precipitation was $450.0 \mathrm{~mm}$, which was $35.0 \mathrm{~mm}$ higher than the average long-term norm. During the growing season, 2018-2019 total precipitation was $677.6 \mathrm{~mm}$, which was $262.6 \mathrm{~mm}$ higher than the average long-term norm. Precipitation during the autumn period was $133.5 \mathrm{~mm}$, winter had $124.2 \mathrm{~mm}$, spring had $253.8 \mathrm{~mm}$ and summer had $166.1 \mathrm{~mm}$. During the growing season, 2019-2020 total precipitation was $677.4 \mathrm{~mm}$, which was $262.4 \mathrm{~mm}$ higher than the average long-term norm. During that period, precipitation of autumn was $144.5 \mathrm{~mm}$, winter had $140.8 \mathrm{~mm}$, spring had $272.9 \mathrm{~mm}$ and summer saw precipitation of $119.2 \mathrm{~mm}$. The fertilizer application scheme for winter wheat of 3 varieties viz. Bezostaya 100, Grom and Aliya (on irrigation) was designed to obtain grain yield of $4,6,8 \mathrm{t} / \mathrm{ha}$ respectively and tested under regime of 1) no fertilizer, 2) $\mathrm{N}_{90} \mathrm{P}_{60} \mathrm{~K}_{45}$, 3) $\mathrm{N}_{120} \mathrm{P}_{90} \mathrm{~K}_{60}$ and 4) $\mathrm{N}_{150} \mathrm{P}_{120} \mathrm{~K}_{90}$. Soil agrochemical properties were established according to the chemical methods of evaluation (Mineeva 2001). Standard plot size was taken as $5 \mathrm{~m}^{2}$ and samples were taken with an agrochemical auger in the range of 10-15 spots per plot. Winter wheat was planted in the middle of October and the analyses were performed in 4 replications. NDVI index was determined using portable spectroradiometer known as Green Seeker (Hand Held Optical Sensor Unit, Model 505, NTech Industries, USA) and Orthomosaic image. NDVI probing of the vegetation index was carried out for wheat at three differentiated levels viz. varieties, fertilizers and irrigation. For varieties Bezostaya 100, Grom, and Aliya, NDVI measurements were performed from the tillering phase to earing for each plot. The yield parameters of winter wheat were evaluated randomly by cutting of 30 productive stems from each experimental plot. In addition, the technical means used in the implementation of precision farming technology in the cultivation of major crops in the farms of the Almaty region were identified and for the analysis technical parameters included were (i) global positioning technologies (GPS, GLONASS), (ii) GIS yield assessment technologies (Yield Monitor Technologies), (iii) variable rationing (Variable Rate Technology; Remote Sensing [Landsat Science Product]). The data from the analysis was corroborated with the heterogeneity of agrochemical indicators for the experimental field following data from the Department of Agrochemistry and Agroecology of Soils, KazRIAPG. The data were statistically analyzed using analysis of variance (ANOVA) by Prism 9.0.1 software. F test was performed to see the significance of the treatment effects. The difference between the means was estimated using the least significant difference and Duncan's multiple range tests at the 5\% probability level. Correlation analyses were performed using the data analysis tool pack of MS Excel (2018). QGIS was used for classification and plotting of NDVI raster. 


\section{RESULTS AND DISCUSSION}

The vegetation index NDVI is the most reliable of the spectral indices when evaluating agricultural crops. The NDVI index for winter wheat sowing after overwintering was 0.18 , which indicates that the plants entered the winter season at an early phenological phase, before tillering. In the 'booting' phase, the index value was average 0.51 units. This indicator designates that the health of the plants is in satisfactory condition. To create a map of the NDVI spectral index, ultra-spectral images were taken (Figure 3).

The ranks of fields according to the state of crops on them were highlighted as an indirect characteristic of the actual soil fertility. The total variation was from 0.62 in the minimum (Bezostaya 100, N90P60K45, 2017/18) to 0.88 in the maximum (Aliya, N150P120K90, 2019/20) in the flowering phase of wheat plants. In the $2017 / 18$ season, the maximum value of the NDVI index differed in the wheat genotypes, the highest value of NDVI (0.79-0.86) was observed under fertilization $\mathrm{N}_{150} \mathrm{P}_{120} \mathrm{~K}_{90}$ (Figure 4). However, fertilization by $\mathrm{N}_{90} \mathrm{P}_{60} \mathrm{~K}_{45}$ provided low index of
NDVI compared to higher concentrations of nitrogen, phosphorus and potassium. In the 2018/19 season NDVI index was lower than the $2017 / 18$ season, which made up $0.69 ; 0.65 ; 0.75$ in the treatments $\mathrm{N}_{90} \mathrm{P}_{60} \mathrm{~K}_{45}, 0.76 ; 0.72$; 0.70 in $\mathrm{N}_{120} \mathrm{P}_{90} \mathrm{~K}_{60}$, and $0.85 ; 0.75 ; 0.79$ in $\mathrm{N}_{150} \mathrm{P}_{120} \mathrm{~K}_{90}$ fertilization plots in Aliya, Bezostaya 100 as well as Grom, respectively. The highest NDVI index was observed $(0.88$; $0.70 ; 0.76$ ) in the $2019 / 20$ season compared to $2017 / 18$ and 2018/19 seasons in $\mathrm{N}_{150} \mathrm{P}_{120} \mathrm{~K}_{90}$ fertilization plots in Aliya, Bezostaya 100 as well as Grom, respectively. On the other hand, the highest NDVI index (0.76 and 0.78) was observed in the 2017/18 season in the variety Bezostaya 100 compared to Aliya in the $\mathrm{N}_{90} \mathrm{P}_{60} \mathrm{~K}_{45}$ and $\mathrm{N}_{120} \mathrm{P}_{90} \mathrm{~K}_{60}$ treatments. Similarly, the highest NDVI index was 0.75 for the variety Grom in the $\mathrm{N}_{90} \mathrm{P}_{60} \mathrm{~K}_{45}$ compared to Aliya (2018/19), respectively. In comparison with grain yield, the value of the NDVI index high correlated for Bezostaya 100 (r-0.89), and Grom (r-0.83). Overall, the highest NDVI index was observed in the $\mathrm{N}_{150} \mathrm{P}_{120} \mathrm{~K}_{90}$ in the winter wheat variety Aliya in all three seasons.

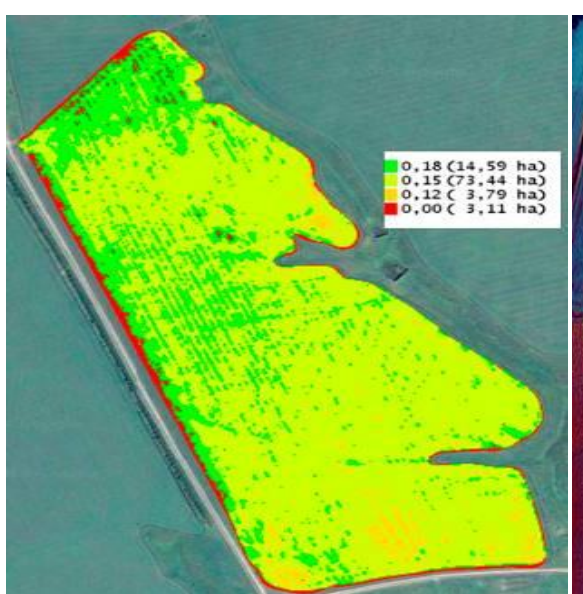

A

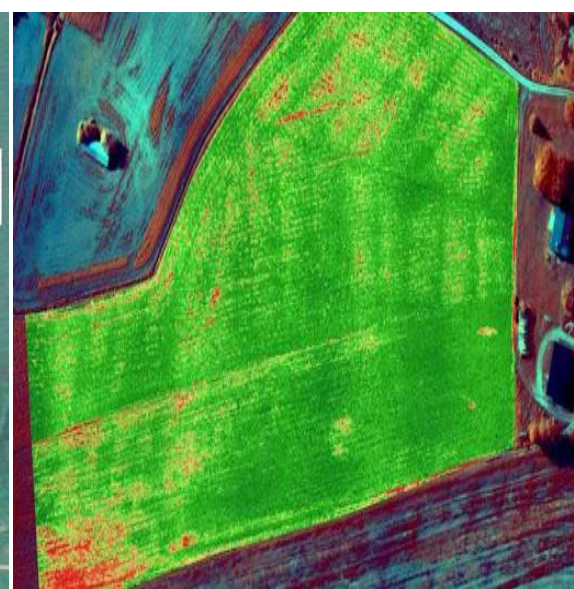

B

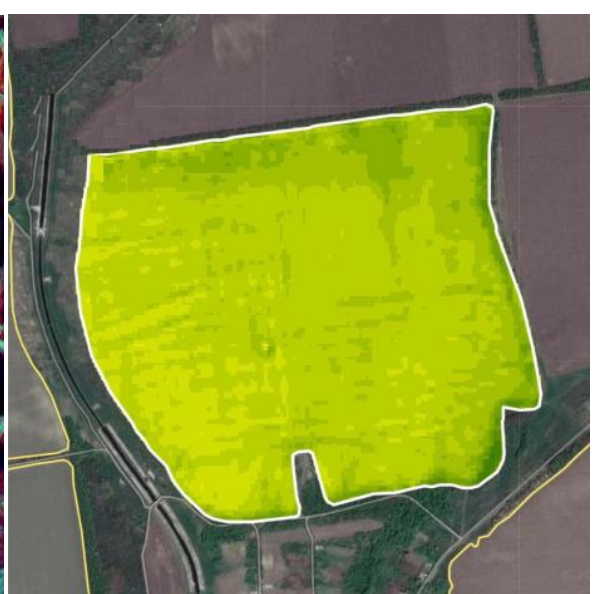

C

Figure 3. NDVI map of winter wheat variety Aliya (A), Bezostaya 100 (B) and Grom varieties (C), at tillering stage, (GS-25, Zadoks, 1974), Almalybak, Kazakhstan

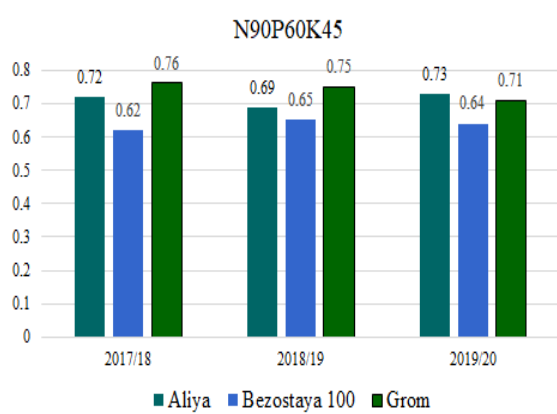

$\mathbf{A}$

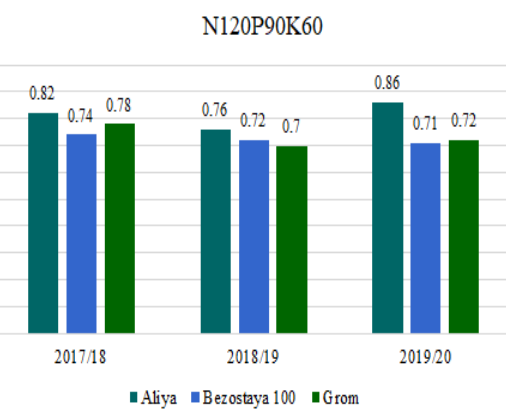

$\mathbf{B}$

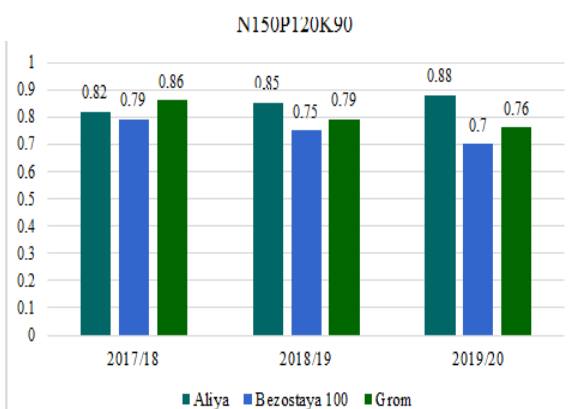

C

Figure 4 (A-C). The NDVI index of three winter wheat varieties at flowering stage (GS-58, Zadoks 1974), Almalybak, Kazakhstan 


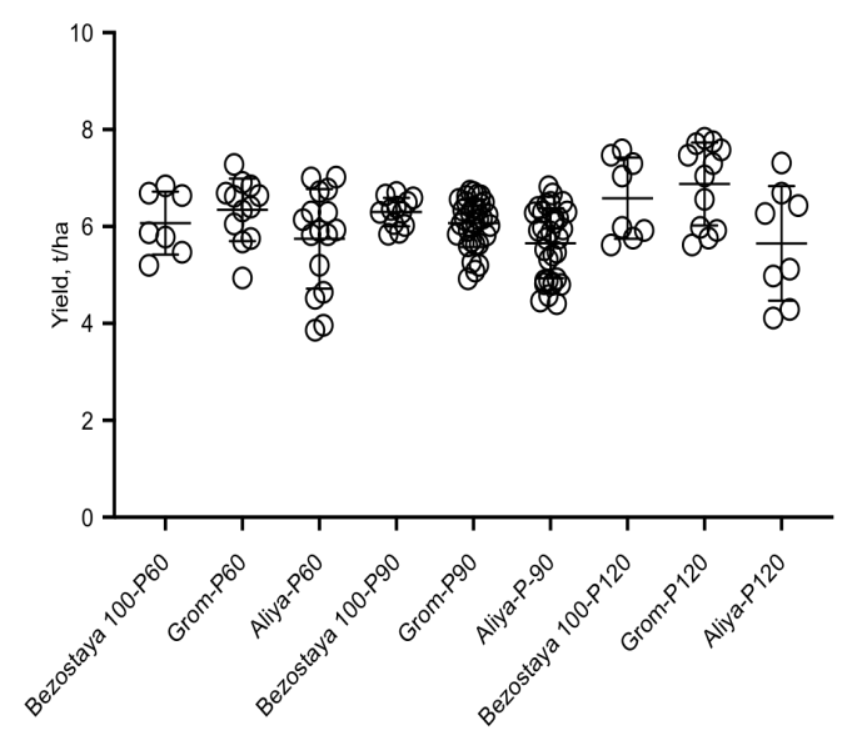

P-phosphorus, 60, 90, $120 \mathrm{~kg} / \mathrm{ha}$

Figure 5. Yield of winter wheat varieties affected by phosphorus fertilizer concentrations $(60,90,120 \mathrm{~kg} / \mathrm{ha})$

In the $2^{\text {nd }}$ experiment, the effect of only phosphorus fertilizers on winter wheat varieties in 3 different concentrations, such as $\mathrm{P}_{60}, \mathrm{P}_{90}$, and $\mathrm{P}_{120}$ were studied. Figure 5 demonstrates the yield of winter wheat varieties such as Bezostaya 100, Grom, and Aliya. As can be seen from the graph the yield of wheat varieties was almost the same under different doses of phosphorus fertilizer. In plots with $\mathrm{P}_{120}$, the mean yield of Bezostaya 100 and Grom was high with 6.7-7.0 tonnes. However, the mean yield of variety Aliya was the around same for the doses of $\mathrm{P}_{60}$ and $\mathrm{P}_{90}$. The yield of variety Grom under $\mathrm{P}_{60}$ was 6.5 tonnes, while under same phosphorus regime productivity of Bezostaya 100 and Aliya was less. The highest amount of mean yield was observed for Bezostaya 100 and Grom under $\mathrm{P}_{120}$ doses. This study revealed that $\mathrm{P}_{120}$ doses were more suitable in experimental plots for winter wheat.

The mean grain yield for three growing seasons of mineral fertilization for the studied varieties varied from 4.2 to $7.6 \mathrm{t} / \mathrm{ha}$ for Aliya, for Bezostaya 100 it ranged from 4.0 to $6.8 \mathrm{t} / \mathrm{ha}$ and for Grom it was from 4.5 to $7.9 \mathrm{t} / \mathrm{ha}$. The data presented in Figure 6 shows that regardless of the varieties used, the intensification of cultivation technology on winter wheat significantly increased grain yield and its maximum value was noted when using intensive technology in the precision farming system (on average, over the years of study, Aliya variety $-7.69 \mathrm{t} / \mathrm{ha}$, Bezostaya $100-6.8$ t/ha and Grom 7.9 t/ha).

\section{Discussion}

Winter wheat can produce high grain yields if it is grown under favorable conditions. Long-term studies by scientists of KazRIAPG have developed optimal application rates of mineral fertilizers for various soil and climatic conditions, yield levels, as well as the timing and methods of their application, considering the needs and

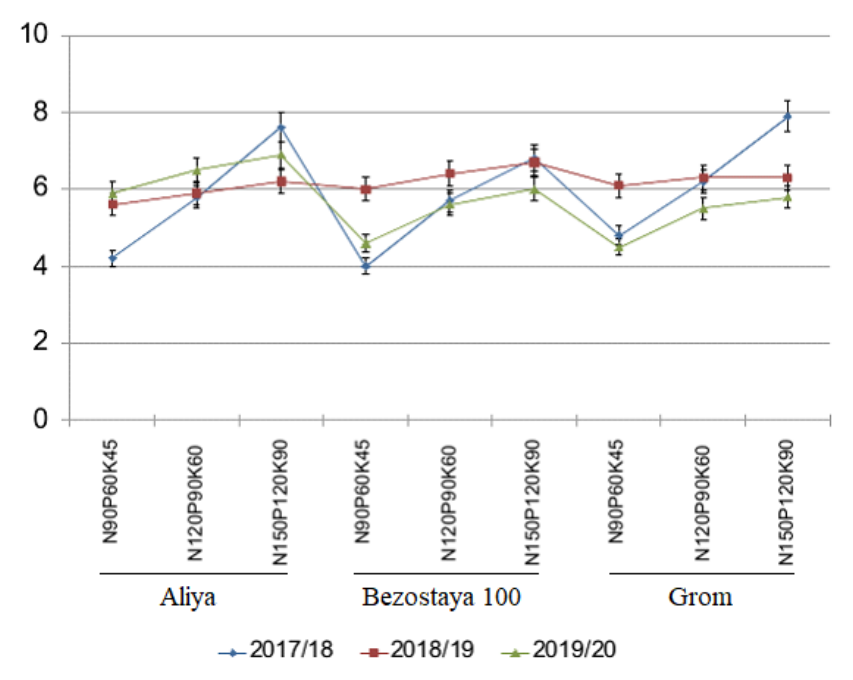

Figure 6. The yield of winter wheat varieties at different levels of NPK fertilization, t/ha $(2017 / 18,2018 / 19,2019 / 20)$

stage of plant development. The obtained results are currently used in the development of agricultural technologies in the system of precision farming. In recent years, radio-controlled unmanned aerial vehicles intended for operational inspection of agricultural land and monitoring the condition of crops have become widespread. The mobility of obtaining and processing information makes it possible to identify homogeneous technological zones for agricultural activities, in particular, differentiated application of mineral fertilizers whenever necessary. Extremely important in increasing the productivity of winter wheat is the timely application of nutrition of plants with fertilizers. The high efficiency of early spring nitrogen feeding is explained by the fact that winter wheat plants resume their weakened vegetation after overwintering. In early spring, their intensive growth and intensive nitrogen consumption begin, and nitrogen mineralization in the soil during this period is weak due to low temperature and high soil moisture. Thus, the nutrition factor of plants in conditions of an optimal level of soil moisture contributed to the formation of an assimilation apparatus of considerable size, especially when applying high fertilizer rates. The differential application of phosphorus fertilizers during the reporting year was able to improve the availability of experimental field with mobile phosphorus. Various studies have developed a diagnosis of the mineral nutrition of winter wheat. The periods critical in the formation of the crop are determined when the plants most need fertilizers and their greatest effectiveness is manifested. It was shown that timely nitrogen top dressing can enhance productive tillering, increase the number of grains in an ear, and improve grain quality (Sapakhova 2014). The more favorable the conditions for the growth and development of winter wheat plants during tillering 
and the beginning of trumping, the larger the ear is laid and the higher the yield (Suleimenova et al. 2020b).

Monitoring of the wheat genotypes using GreenSeeker, an optical sensor, showed a change in the plant biomass index (NDVI) value depending on the conditions of cultivation and the phase of development. An association ( $r$ $=0.64$ ) between NDVI and the yield of winter wheat was established in similar experiments in this region (Yessimbekova et al. 2019). The map data for the NDVI index can be used for the differentiated application of nitrogen fertilization. At the same time, it is necessary to allocate zones of high, medium and low vegetation, and if the vegetation index on the site is high, then the dose of fertilizers should be reduced by $10-30 \%$ of the average rate.

In conclusion, the highest NDVI index was observed in the high concentrations of NPK $\left(\mathrm{N}_{150} \mathrm{P}_{120} \mathrm{~K}_{90}\right)$ in the winter wheat varieties. Application of only phosphorus fertilizer increased mean yield from 5.3 to 6.8 t/ha. The grain yield on mineral fertilization for the studied variety varied for winter wheat varieties varied from 4.0 to $7.9 \mathrm{t} / \mathrm{ha}$ on average for 3 different concentrations of fertilizers. High concentrations of NPK $\left(\mathrm{N}_{150} \mathrm{P}_{120} \mathrm{~K}_{90}\right)$ increased mean grain yield from $5.8 \mathrm{t} / \mathrm{ha}$ to $7,9 \mathrm{t} / \mathrm{ha}$ in three wheat varieties (Aliya $6.9 \mathrm{t} / \mathrm{ha}$; Bezostaya 100-6.5 t/ha; Grom-6.7 t/ha in average) compared to control, where yield was $3.5 \mathrm{t} / \mathrm{ha}$. Fertilizer application in high concentrations increased the wheat plant NDVI index (Bezostaya 100-0.79; Grom-0.85; Aliya-0.86) and grain yield of winter wheat varieties. Therefore, map data for the NDVI index can be used for the differentiated application of nitrogen, phosphorus, and potassium fertilizers. Also, it is important to investigate the plant (variety) specific fertilizers, as it allows to increase the economic efficiency of crop yield.

\section{ACKNOWLEDGEMENTS}

This research was funded by a grant "Develop and implement effective production control technologies for irrigated land" (\#118PK01213) of the Ministry of Agriculture of the Republic of Kazakhstan.

\section{REFERENCES}

Bastaubayeva SO, Ramazanova SB. 2018. Management techniques for the production process of grain crops in the system of precision farming. In: Materials of the II All-Russian Conf. The use of remote sensing of the Earth in agriculture. St. Petersburg. 168-170. [Russian].

Gebbers R, Adamchuk VI. 2010. Precision agriculture and food security. Science 327: 828-831. DOI: 10.1126/science.1183899.

Diacono M, Rubino P, Montemurro F. 2013. Precision nitrogen management of wheat. A review. Agron Sustain Dev 33: 219-241. DOI: $10.1007 / \mathrm{s} 13593-012-0111-\mathrm{z}$.

Kokhmetova A, Sapakhova Z, Urazaliev R, Yessimbekova M, Yeleshev R., Morgounov A. 2014. Effect of spring biomass removal on expression of agronomic traits of winter wheat. World Appl Sci J 30: 322-329.

Martínez-Castillo R. 2016. Sustainable agricultural production systems. Technol Marcha 29: 70-85. DOI: 10.18845/tm.v29i5.2518

Meena AK, Meena RN, Singh T, Meena AK, Yadav TK. 2019. Use of precision agriculture for sustainability and environmental protection. In: Rawat AK, Tripathi UK (eds.) Advances in Agronomy, Volume 5. AkiNik Publications. New Delhi.

Mineeva VG. 2001. Practicum on agrochemistry. Moscow State University Publishing House. Moscow. [Russian]

Morgounov A, Akin B, Demir L, Keser M, Kokhmetova A, Martynov S, et al. 2015. Yield gain due to fungicide application in varieties of winter wheat (Triticum aestivum) resistant and susceptible to leaf rust. Crop Pasture Sci 66: 649-659. DOI: 10.1071/CP14158.

Mousazadeh H. 2013. A technical review on navigation systems of agricultural autonomous off-road vehicles. J Terramechanics 50: 211232. DOI: 10.1016/j.jterra.2013.03.004.

Romaneckas K, Zinkevicius R, Steponavicius D, Maziliauskas A, Butkus V, Marcinkeviciene A. 2015. Principles of precision agriculture in onfarm spring wheat fertilization experiment. Eng Rural Dev 14: 558563.

Sapakhova ZB. 2014. Development of a system for the use of fertilizers and fungicides on winter wheat varieties resistant to leaf rust. [Dissertation]. Almaty, Kazakhstan. [Russian].

Schmidhalter U, Maidl FX, Heuwinkel H, Demmel M, Auernhammer H, Noack PO, Rothmund M. 2008. Precision Farming-Adaptation of Land Use Management to Small Scale Heterogeneity. In: Schröder P, Pfadenhauer J, Munch JC. (eds.). Perspectives for Agroecosystem Management: Balancing Environmental and Socio-Economic Demands. 2008: 121-199. DOI: 10.1016/B978-044451905-4.50007-6.

Truflyak EV. 2016. The main elements of a precision farming system. KubSAU, Krasnodar. [Russian].

Yakushev VP, Yakushev VV, Blokhina SY. 2020. Scientific background of intellectual system development for precision agriculture. Plant Prot News 103: 25-36. DOI: 10.31993/2308-6459-2020-103-1-25-36.

Yessimbekova MA, Suleimenova MS, Mukin KB. 2019. Wheat genetic resources for breeding on adaptability. Curr Chall Plant Genet, Genom, Bioinform Biotechnol 21-23 DOI: 10.18699/ICGPlantGen2019-04

Zarco-Tejada PJ, Hubbard N, Loudjani P. 2014. Precision agriculture: an opportunity for EU farmers-potential support with the CAP 20142020. Joint Research Centre (JRC) of the European Commission, Brussel. https://www.europarl.europa.eu/ 